\title{
Optimization of a forest road network
}

P. J. M. Wijngaard and M. P. Reinders (Department of Forest Technique and Forest Products, Agricultural University, P.O. Box 342, 6700 AH Wageningen, Netherlands

Received 17 December 1984; accepted 28 February 1985

\begin{abstract}
A new model that can be used to plan forest road networks has been developed. It differs from parallel network systems, which have often been used in other models. The new model can be used for either flat or broken ground. It makes use of modern techniques from operations research (e.g. Travelling Salesman algorithm) and computer science (e.g. data-base management systems).
\end{abstract}

Key-words: forest road networks, operations research, Dijkstra algorithm, nonparallel roads, broken ground.

Introduction. All other models that can be used to plan forest road networks are based on a parallel network. All roads are parallel and equidistant. The distance apart is defined analytically by minimizing total costs (comprising loading costs, road costs, transport costs and costs before hauling; App. A; Larsson, 1959). If the terrain is broken, then the calculated road network will be shifted (as a whole) until the result is satisfactory (Bryer, 1983). Such an approach is never optimum. It is better to include terrain in the model. It is also preferable to include non-quantitative factors in the model. So a model has been developed that can calculate networks also in situations that cannot be adequately handled by older models.

\section{Material and methods}

\section{Model for flat terrain and non-parallel road networks}

This model is as follows. The model, contrary to other models, considers the whole area. The area is divided into compartments of variable size. The trees or logs are concentrated in the centre of every compartment by skidder or horse. So, piles of wood arise in these centres. We assume that a network has to be built that enables us to pick up all the piles of wood. With a heuristic Travelling-Salesman solver (Beek \& Hendriks, 1983), we can calculate a network with a shape that minimizes the total costs. By varying the size of the compartments, an optimum solution can be found. This is all achieved by an iterative process (App. A).

\section{Model for broken terrain and non-parallel road networks}

In flat terrain, a road connects two piles of wood in a straight line. But in broken terrain, this is not necessarily the cheapest way. For example, one might encounter impractical slopes. To avoid that, the model works as follows. A topographic screen 
where the angular points contains altitudes, will be projected onto the compartments screen. The centre of every compartment (where the pile of wood is situated) will be shifted to the nearest angular point of the topographic screen (mostly a shift by a maximum of $5 \mathrm{~m}$; the difference in height is minimal). We then know the altitude where the pile of wood is situated. The search starts for the shortest route from pile to pile over the angular points. The search for the shortest route is executed with a shortest-path method (Dijkstra algorithm; Koppe, 1981). It is also possible to include an already existing road (for instance the nearest metalled road). The network can be calculated with the Travelling-Salesman solver using the shortest routes (App. A).

Software (written in FORTRAN 77) was developed for this model. It makes use of a data-base management system (1022-system; Software House, 1983) and plotter-application software. The data base serves as a replacement for virtual memory (the program has a lot of variables). Also one can use the data sets outside the program either to look at the results or to create a new input for further runs. The program has been developed on a DEC-10 computer (operating system TOPS-10 V701; software Galaxy V4.1).

Conclusions. One can solve for different terrains, for instance already existing roads, rivers, protected areas and soil conditions (e.g. swamps). As yet, only altitude has been used in this model, shown as a one-dimensional vector superimposed on the angular points of the topographic screen. Other land conditions would make this vector multidimensional. As element, one could take binary variables (e.g. an already existing road meeting an angular point of the topographic screen is assigned the binary value 1 ; otherwise, 0 ). The model can only be used for rectangular areas. More complex situations of the terrain can be built into the multidimensional vectors. By adjusting costs, one can now choose suboptimal solutions including non-quantitative factors such as recreation.

In situations in which transport costs play an important role, the model leads to cheaper results than can be obtained with other models (Larsson, 1959). The program is still slow and makes heavy demands on virtual and background memory.

\section{Appendix A.}

1 In the Larsson model, the roads are equidistant.

$$
a= \pm(y / p \cdot t(r))^{1 / 2}
$$

With:

$$
\begin{array}{ll}
\mathrm{y}, & \text { annual road costs } \\
\mathrm{p}, & \text { average production } \\
\mathrm{t}(\mathrm{r}), & \text { hauling costs, variable } \\
\mathrm{a}, & \text { road distance, half }
\end{array}
$$

$$
\begin{aligned}
& (\mathrm{m}) \\
& \left(\mathrm{m}^{3} \cdot \mathrm{m}^{-2}\right) \\
& \left(\mathrm{f} \cdot \mathrm{m}^{-3} \cdot \mathrm{m}^{-1}\right) \\
& (\mathrm{m})
\end{aligned}
$$


2 Model for flat terrain and non-parallel road networks

$$
\begin{aligned}
& \text { TOTCST }=\text { VASTSK }+ \text { VARSK } \cdot S L+ \\
& +\{(\mathrm{B}-5) \cdot(\mathrm{O}-\mathrm{H})+\mathrm{RCC}+\mathrm{RCM}\} \cdot \mathrm{WL}+\mathrm{L}+\mathrm{WTK} \cdot \mathrm{GEAFW}
\end{aligned}
$$

With:

$$
\begin{aligned}
& \mathrm{WL}=\sum_{0}^{\alpha} \mathrm{A} / \mathrm{M}+\sum_{0}^{\beta} \mathrm{B} / \mathrm{N}+\sum_{0}^{\gamma}\left(\mathrm{A}^{2} / \mathrm{M}^{2}+\mathrm{B}^{2} / \mathrm{N}^{2}\right)^{1 / 2}+\sum_{\mathrm{v}=\mathrm{v} 1}^{\mathrm{v} 2} \mathrm{~A} / 2 \mathrm{M}+\sum_{\mathrm{u}=\mathrm{u} 1}^{\mathrm{u} 2} \mathrm{~B} / 2 \mathrm{~N} \\
& \mathrm{GEAFW}=\left\{\sum_{\mathrm{v} 1}^{\mathrm{v} 2}\left(\sum_{\mathrm{r}=1}^{\mathrm{N} \cdot \mathrm{M}}\left(\sum_{0}^{\alpha(\mathrm{r})} \mathrm{A} / \mathrm{M}+\sum_{0}^{\beta(\mathrm{r})} \mathrm{B} / \mathrm{N}+\sum_{0}^{\gamma(\mathrm{r})}\left(\mathrm{A}^{2} / \mathrm{M}^{2}+\mathrm{B}^{2} / \mathrm{N}^{2}\right)^{1 / 2}\right)+\mathrm{A} / 2 \mathrm{M}\right)\right\} \\
& \left.(\mathrm{N} \cdot \mathrm{M})+\sum_{\mathrm{u} 1}^{\mathrm{u} 2}\left(\sum_{\mathrm{r}=1}^{\mathrm{N} \cdot \mathrm{M}}\left(\sum_{0}^{\alpha(\mathrm{r})} \mathrm{A} / \mathrm{M}+\sum_{0}^{\beta(\mathrm{r})} \mathrm{B} / \mathrm{N}+\sum_{0}^{\gamma(\mathrm{r})}\left(\mathrm{A}^{2} / \mathrm{M}^{2}+\mathrm{B}^{2} / \mathrm{N}^{2}\right)^{1 / 2}\right)+\mathrm{B} / 2 \mathrm{~N}\right) /(\mathrm{N} \cdot \mathrm{M})\right\} / \mathrm{W}
\end{aligned}
$$

$(\mathrm{B}-5) \cdot(\mathrm{O}-\mathrm{H})$ means forest production loss due to road construction; when the road is smaller than $5 \mathrm{~m}$, there is no production loss.

SL: see Model 3

3 Model for broken terrain and non-parallel road networks

TOTCST $=$ VASTSK + VARSK $\cdot S L+\{(\mathrm{B}-5) \cdot(\mathrm{O}-\mathrm{H})+\mathrm{RCC}+\mathrm{RCM}\} \cdot \mathrm{WL}+$ $+\mathrm{L}+\mathrm{WTK} \cdot \mathrm{GEAFW}$

With:

$$
\begin{aligned}
& \mathrm{SL}=\left\{2\left(\mathrm{~B}^{2} / \mathrm{N}^{2}+\mathrm{A}^{2} / \mathrm{M}^{2}\right)^{1 / 2}+\mathrm{A} / \mathrm{M}+\mathrm{B} / \mathrm{N}\right\} /(2 \cdot(4+2 / \mathrm{N}+2 / \mathrm{M})) \\
& \mathrm{WL}=\sum_{\mathrm{t}=0}^{\mathrm{T} 1(\mathrm{r})} \mathrm{X}(\mathrm{x}(\mathrm{t}), \mathrm{y}(\mathrm{t}))+\sum_{\mathrm{t}=0}^{\mathrm{T} 2(\mathrm{r})} \mathrm{X}(\mathrm{x}(\mathrm{t}), \mathrm{y}(\mathrm{t})) \\
& \mathrm{X}(\mathrm{x}(\mathrm{t}), \mathrm{y}(\mathrm{t}))=\left\{\mathrm{G}^{2}\right\}^{1 / 2} \\
& \mathrm{G}=|\mathrm{i}(\mathrm{t})| \cdot \mathrm{MC}^{2}+|\mathrm{j}(\mathrm{t})| \cdot \mathrm{NC}^{2}+\mathrm{Max}(|\mathrm{i}| \cdot|\mathrm{j}|) \cdot\{\mathrm{H}(\mathrm{x}(\mathrm{t}+1), \mathrm{y}(\mathrm{t}+1))-\mathrm{H}(\mathrm{x}(\mathrm{t}), \mathrm{y}(\mathrm{t}))\} \\
& \mathrm{GEAFW}=\mathrm{WL}(\mathrm{u})+\mathrm{WL}(\mathrm{v}) \\
& \mathrm{WL}(\mathrm{v})=\left(\sum_{\mathrm{v}=\mathrm{v} 1}^{\mathrm{v} 2}\left\{\sum_{\mathrm{r}=1}^{\mathrm{N} \cdot \mathrm{M}}\left\{\sum_{\mathrm{t}=0}^{\mathrm{T} 1(\mathrm{r})} \mathrm{X}(\mathrm{x}(\mathrm{t}), \mathrm{y}(\mathrm{t}))+\sum_{\mathrm{t}=0}^{\mathrm{T} 2(\mathrm{r})} \mathrm{X}(\mathrm{x}(\mathrm{t}), \mathrm{y}(\mathrm{t}))\right\}\right\}\right) /(\mathrm{N} \cdot \mathrm{M} \cdot \mathrm{W}) \\
& \mathrm{WL}(\mathrm{u})=\left(\sum_{\mathrm{u}=\mathrm{u} 1}^{\mathrm{u} 2}\left\{\sum_{\mathrm{r}=1}^{\mathrm{N} \cdot \mathrm{M}}\left\{\sum_{\mathrm{t}=0}^{\mathrm{T} 1(\mathrm{r})} \mathrm{X}(\mathrm{x}(\mathrm{t}), \mathrm{y}(\mathrm{t}))+\sum_{\mathrm{t}=0}^{\mathrm{T} 2(\mathrm{r})} \mathrm{X}(\mathrm{x}(\mathrm{t}), \mathrm{y}(\mathrm{t}))\right\}\right\}\right) /(\mathrm{N} \cdot \mathrm{M} \cdot \mathrm{W}) \\
& \mathrm{i}(\mathrm{t})=\mathrm{x}(\mathrm{t}+1)-\mathrm{x}(\mathrm{t}) \\
& j(t)=y(t+1)-y(t)
\end{aligned}
$$




\section{Model 2 and Model 3, variables}

\begin{tabular}{|c|c|c|}
\hline TOTCST, & total costs & $\left(f \cdot m^{-3}\right)$ \\
\hline VASTSK, & hauling costs, fixed & $\left(\mathrm{f} \cdot \mathrm{m}^{-3}\right)$ \\
\hline VARSK, & hauling costs, variable & $\left(f \cdot m^{-3} \cdot m^{-1}\right)$ \\
\hline & hauling distance & (m) \\
\hline $\mathrm{B}$ & width of road & (m) \\
\hline $\mathrm{O}$ & logging costs & $\left(f \cdot m^{-3}\right)$ \\
\hline $\mathrm{H}$ & growing costs & (f. $\mathrm{m}^{-3}$ growth) \\
\hline WL, & total length of road & (m) \\
\hline $\mathrm{L}$ & loading costs & $\left(\mathrm{f} \cdot \mathrm{m}^{-3}\right)$ \\
\hline WTK, & transport costs & $\left(f \cdot m^{-3} \cdot m^{-1}\right)$ \\
\hline $\begin{array}{l}\text { GEAFW, } \\
\text { RCC }\end{array}$ & transport distance for whole area (average) & $(m)$ \\
\hline RCM & $\begin{array}{l}\text { road construction costs } \\
\text { road costs (upkeep) }\end{array}$ & $\left(\mathrm{f} \cdot \mathrm{m}^{-1}\right)$ \\
\hline $\mathrm{A} \cdot \mathrm{B}$ & size of whole area & $\left(\mathrm{m}^{2}\right)$ \\
\hline $\mathrm{M} \cdot \mathrm{N}$ & number of hauling compartments & (1) \\
\hline $\mathrm{MC} \cdot \mathrm{NC}$ & size of topographic compartment & $\left(m^{2}\right)$ \\
\hline $\mathrm{x}(\mathrm{t}), \mathrm{y}(\mathrm{t})$ & $\begin{array}{l}\text { coordinates belonging to angular point t } \\
\text { (topographic screen) }\end{array}$ & (1) \\
\hline $\mathrm{H}$ & altitude & (m) \\
\hline $\mathrm{T} 1(\mathrm{r})$, & $\begin{array}{l}\text { total of angular points passing by when } \\
\text { going to pile number } r \text { (in the network) }\end{array}$ & (1) \\
\hline $\mathrm{T} 2(\mathrm{r})$ & $\begin{array}{l}\text { total of angular points passing by when } \\
\text { going to pile number } r \text { (to the network) }\end{array}$ & (1) \\
\hline $\mathrm{v} 2$, & number of forst entrances (East and West side) & (1) \\
\hline $\mathrm{u} 2$, & number of forest entrances (North and South side) & (1) \\
\hline$\alpha$ & $\begin{array}{l}\text { total number roads connecting piles } \\
\text { (East-West direction) }\end{array}$ & (1) \\
\hline$\beta$, & $\begin{array}{l}\text { total number roads connecting piles } \\
\text { (North-South direction) }\end{array}$ & (1) \\
\hline , & total number roads connecting piles (diagonal) & (1) \\
\hline & total of forest entrances & (1) \\
\hline
\end{tabular}

\section{References}

Beek, P. van \& Th. H. B. Hendriks, 1983. Optimaliseringstechnieken, principes en toepassingen, Bohn, Scheltema \& Holkema, Utrecht.

Bryer, J. B., 1983. The effects of a geometric redefinition of the classical road and landing spacing model through shifting. Forest Science 29 (3): 670-674.

Koppe, W. P., 1981. Berekening van de kortste en N-na kortste paden in een wegennetwerk. M. Sc. thesis, Mathematical Department, Wageningen (unpublished).

Larsson, G., 1959. Studies on forest road planning. Transactions of the Royal Institute of Technology, Stockholm, Sweden 147.

Software House, 1983. System 1022 Users Reference Manual. Cambridge, Massachusetts, US. 
This synopsis is based on a student thesis entitled 'De optimalisatie van een wegennet in beboste gebieden - een nieuw model voor zowel vlak als geaccidenteerd terrein' by M. P. Reinders \& P. J. M. Wijngaard, Department of Forest Technique and Forest Products, Agricultural University, Wageningen, 1984. vi +161 pp., 32 figs., 29 refs., appendices. Dutch, English summary.

Available as paper copy (order R033P, $f 30$ including postage) or on microfiche (order R033M, f 17,50 including postage) at: NARD, clo Pudoc, P.O. Box 4, 6700 AA Wageningen, Netherlands (telex 45015 blhwg $\mathrm{nl}$ ).

\section{Growth and morphogenesis of shoot initials of Douglas fir, Pseudotsuga menziesii (Mirb.) Franco, in vitro}

P. W. Evers (Dorschkamp Research Institute for Forestry and Landscape Planning, P.O.Box 23, 6700 AA Wageningen, Netherlands)

Received 6 May 1985; accepted 20 May 1985

Abstract. An optimalized method of micropropagation of Douglas fir is described. Seasonal changes were found in optima for nitrate and sucrose in the medium and in the optimum for the light intensity during the culture of shoot initials. Differences in morphogenesis were obtained from shoot initials that had been isolated from buds in 10 topophysical positions on 2-year-old trees. These differences between the shoots were influenced by the medium, the light intensity, and by forcing or topping the mother trees or treating them with growth regulators. Shoots from each of the topophysical positions had a characteristic photosynthesis.

Key words: topophysis, season, photosynthesis, micropropagation

Introduction. In trees showing a basic growth programme, architecture can be used to pin-point physiological gradients. The effect of these gradients is commonly referred to as topophysis. Both architecture and topophysis are thus closely related to basic principles such as physiological ageing (Romberger, 1976); it is therefore obvious that these properties of the tree will often determine the success of vegetative propagation. Thus the growth and differentiation of a tree species have to be studied before methods of vegetative propagation can be developed (Durzan, 1982). Using the technique of micropropagation offered the opportunity of studying morphogenesis of parts of the tree and the consequences of tree physiology in a controlled environment (Campbell \& Durzan, 1976). In the in vitro system, the morphogenesis of tree meristem products can be studied and thus the consequences of 